\title{
Análise Ergonômica do Trabalho em uma Serraria do Estado do Espírito Santo
}

\author{
Lucas Recla Lombardi ${ }^{1}$, Vinnicius Dordenoni Pizzol ${ }^{2}$, Graziela Vidaurre ${ }^{3}$, \\ Rafael Bridi Corteletti ${ }^{4}$, Raul Llobregat Fairbanks Barbosa ${ }^{4}$ \\ ${ }^{1}$ Universidade Federal de Viçosa - UFV \\ ${ }^{2}$ Universidade Federal de Lavras - UFLA
}

${ }^{3}$ Departamento de Engenharia Florestal - DEF, Universidade Federal do Espírito Santo - UFES

${ }^{4}$ Universidade Federal do Espírito Santo - UFES

\begin{abstract}
RESUMO
A análise ergonômica do trabalho visa avaliar, diagnosticar e corrigir uma situação real de um posto de trabalho, proporcionando ao operador melhores condições de trabalho e produtividade. Este trabalho objetivou avaliar o ambiente de trabalho em uma serraria no município de Jerônimo Monteiro-ES, visando à melhoria da saúde, do bem-estar, da segurança e da produtividade dos trabalhadores. Na serraria, determinou-se o nível de ruído por meio de dosímetros e decibelímetro; a iluminação, com auxílio de luxímetro e fotocélula, e o conforto térmico, com base nas médias de temperaturas registradas pelo Índice de Bulbo Úmido e o Termômetro de Globo (IBUTG). Os dados mostraram que o nível de ruído é inaceitável, assim como o sistema de iluminação é inadequado para tal atividade produtiva. O conforto térmico atendeu as conformidades da norma. Assim, é fundamental alterar o sistema de iluminação, utilizando melhor a iluminação natural e reestruturando a iluminação geral e específica nos equipamentos; faz-se também necessário promover o uso de protetores auriculares e instalar dispositivos que minimizem a emissão de ruídos nas máquinas.
\end{abstract}

Palavras-chave: ergonomia, ambiente de trabalho, saúde ocupacional.

\section{Ergonomic Analysis of Work in a Mill in the State of Espirito Santo}

\begin{abstract}
The ergonomic analysis of work aims to evaluate, diagnose and fix a real situation of a job, providing the operator better working conditions resulting in higher productivity. This study aimed to evaluate the working environment at a sawmill in Jeronimo Monteiro, State of Espirito Santo, with the purpose to improve the health, welfare, safety and productivity of workers. The noise level in the sawmill was determined through dosimeters and sound level meters, with the help of a lighting and photocell light meter. The thermal comfort was based on the average temperatures recorded by the WBGT index. The data showed that the noise level was unacceptable and the lighting system inadequate for such production activity. The thermal comfort met the standard of compliance. Thus, it is fundamental to alter the lighting system - making better use of natural light, perform a restructuration of specific equipment, promote the use of ear protectors, and install devices that minimize noise emission from the machinery.
\end{abstract}

Keywords: ergonomics, working environment, occupational health. 


\section{INTRODUÇÃO}

A análise ergonômica visa aplicar os conhecimentos da ergonomia para avaliar, diagnosticar e corrigir uma situação real de um posto de trabalho. O ambiente de trabalho é uma das variáveis que também interfere na produtividade e na segurança do trabalhador (Fiedler \& Souza, 2007).

Segundo Fiedler \& Souza (2007), o trabalhador na indústria madeireira pode estar sujeito a diferentes situações no ambiente de trabalho, como, por exemplo, elevados níveis de ruído e vibração, iluminação insuficiente e desconforto térmico. Além disso, fatores relacionados ao dimensionamento dos postos de trabalho, às ferramentas e às posturas inadequadas durante a execução do serviço também estão presentes na análise ergonômica e estão ligados diretamente à antropometria do trabalhador.

O trabalho em condições climáticas desfavoráveis produz fadiga, extenuação física e nervosa, diminuição do rendimento e aumento dos riscos de acidentes, além de expor o organismo a diversas doenças (Couto, 1987).

A avaliação da exposição a temperaturas excessivas é de grande importância para que se possa garantir o conforto térmico do trabalhador. Existem vários índices para avaliação da exposição ao calor. A Norma Regulamentadora (NR) 15 - Anexo 3 (Brasil, 1978), prescreve o uso do Índice de Bulbo Úmido e o Termômetro de Globo (IBUTG) para tal análise.

A zona de conforto térmico é delimitada pelas temperaturas entre 20 e $24{ }^{\circ} \mathrm{C}$, com umidade relativa de 40 a $80 \%$ e velocidade do ar moderada. As diferenças de temperaturas presentes no mesmo ambiente não devem ser superiores a $4{ }^{\circ} \mathrm{C}$ (Iida, 2005).

O ruído é uma mistura complexa de diversas vibrações, medido em escala logarítmica, cuja unidade é o decibel $(\mathrm{dB})$. O nível de desconforto depende do nível de intensidade do ruído, podendo este interferir diretamente na execução do trabalho e causar danos irreversíveis ao operador (Iida, 2005).

De acordo com a NR-15 (Brasil, 1978), o ruído contínuo de $85 \mathrm{~dB}$ é considerado o máximo tolerado para uma exposição durante 8 horas de jornada diária de trabalho. Acima desses valores, o tempo de exposição deve ser reduzido, pois começam a existir riscos para os trabalhadores expostos continuamente.

A iluminação do ambiente contribui para aumentar a satisfação no trabalho e melhorar a produtividade, além de reduzir a fadiga e os acidentes. O planejamento da iluminação de qualquer posto de trabalho deve ser muito bem feito, levando-se em consideração a iluminação natural e, sempre que necessário, a iluminação artificial. Os níveis mínimos de iluminância a serem obtidos nos locais de trabalho são estabelecidos pela Associação Brasileira de Normas Técnicas- NBR 5413 (Associação..., 1992), sendo que, para o trabalho em serrarias, fica entre 500 e 2000 lux.

O objetivo deste trabalho foi estudar os fatores ergonômicos relacionados com a caracterização do ambiente de trabalho (ruído, luminosidade e conforto térmico), na Serraria do Pandico, no município de Jerônimo Monteiro-ES, visando à melhoria da saúde, do bem-estar, da segurança, do conforto e da produtividade dos trabalhadores nesta área.

\section{MATERIAL E MÉTODOS}

Este trabalho foi executado com dados coletados na Serraria do Pandico, em Jerônimo Monteiro-ES.

A jornada de trabalho dos operadores tinha duração de 8 horas, iniciando-se às 8 horas e encerrando-se às 17 horas, sendo o intervalo de almoço entre 10 horas e 30 minutos e 11 horas e 30 minutos.

A serraria caracteriza-se por um funcionamento descontínuo, existindo momentos em que se cessa a operação, pois não há demanda. Em função do pequeno porte do estabelecimento, caracterizado pela pequena quantidade de funcionários - três no total -, pelo maquinário defasado e pela produção diária descontínua, diversos tipos de serviços são executados; assim, durante os dias de coleta dos dados de iluminação, ruído e conforto térmico, os operários estavam trabalhando na fabricação de portas de madeira maciça e no reaproveitamento de costaneiras obtidas do desdobro de eucalipto.

Para a análise do ambiente da serraria, foram analisadas as variáveis associadas com os índices recomendados pela NR-15 (Brasil, 1978) e NBR 
5413 (Associação..., 1992), ou seja, analisaram-se a intensidade do ruído, o índice de luminosidade e o Índice de Bulbo Úmido e Termômetro de Globo IBUTG, o qual se refere ao conforto térmico.

O ruído foi medido com uso de dois dosímetros: modelo RS232 e dataloger modelo DSS - 500. Durante a coleta, os aparelhos ficavam acoplados à calça do trabalhador e os sensores, próximos ao seu ouvido, conforme NR-15 (Brasil, 1978). Após 6 horas de trabalho, os dados coletados foram compilados, sendo fornecida a dose de ruído de cada dosímetro, em $\mathrm{dB}(\mathrm{A})$.

O nível equivalente de ruído (Leq), que é o nível de ruído ponderado sobre o período de medição, ou seja, o nível de pressão sonora contínuo, em regime permanente, foi calculado pela Equação 1:

$$
L e q=100+16,61 \times \log \frac{\sum d o s e}{\sum t}
$$

em que: Leq: nível equivalente de ruído; dose: média da dose de ruído coletado pelos dosímetros (dB); e t: média do tempo de coleta dos dosímetros (hora).

Além disso, foi utilizado um decibelímetro da marca Instrutherm, modelo DEC -460, para coleta das doses instantâneas de ruído. As leituras do decibelímetro eram realizadas a cada 20 segundos de operação, durante 3 horas, sendo assim para todos os equipamentos utilizados. Os valores foram obtidos em $\mathrm{dB}(\mathrm{A})$.

A avaliação da luminosidade foi feita no local de trabalho, utilizando-se um luxímetro digital com fotocélula, da marca TES, modelo TES 1332A. As leituras foram realizadas no decorrer do dia, a cada 15 minutos, tendo início às 8 horas e 30 minutos e término às 10 horas e 30 minutos, horário de parada para almoço. $\mathrm{O}$ aparelho foi posicionado num plano horizontal, onde eram feitas as diversas atividades, obtendo-se a leitura em lux.
A análise de conforto térmico dos postos de trabalho foi feita utilizando um IBUTG da marca Metrosonics Inc. modelo HS - 3600, considerandose ambientes internos, sem carga solar. $\mathrm{O}$ aparelho foi instalado no interior da serraria em uma bancada, a 1,5 m do solo. Foram feitas leituras a cada 15 minutos, durante 3 horas, totalizando oito medições.

\section{RESULTADOS E DISCUSSÃO}

Os resultados das análises de ruído das diferentes atividades realizadas nas operações foram obtidos a partir dos dados fornecidos pelos dois dosímetros utilizados. O dosímetro 1 forneceu uma dose de 77,48 $\mathrm{dB}(\mathrm{A})$ em 5,1 horas de coleta. O dosímetro 2 forneceu uma dose de 76,22 $\mathrm{dB}(\mathrm{A})$ em 5,9 horas de coleta.

Assim, utilizando a Equação 1, foi calculado o Leq durante o período de operação, sendo encontrado um nível sonoro equivalente de 119,02 dB (A).

As análises dos ruídos instantâneos coletados com o decibelímetro (Tabela 1 ) foram baseadas na NR-15 (Brasil, 1978). De acordo com essa norma, o limite máximo de exposição durante 8 horas de trabalho contínuo é de $85 \mathrm{~dB}(\mathrm{~A})$, sendo que o valor verificado encontra-se $40 \%$ acima do estipulado. Caso este requisito não seja atendido, a jornada de trabalho deverá ser reduzida em função do aumento da intensidade sonora.

A redução da jornada ocorre de modo proporcional: a cada $5 \mathrm{~dB}$ de excesso, reduz-se à metade da carga de trabalho.

$\mathrm{Na}$ Tabela 1, ressalta-se que a respigadeira e a serra circular operam acima do limite de exposição máxima de ruído $[85 \mathrm{~dB}(\mathrm{~A})]$, sendo a respigadeira excedendo $4,42 \%$ e a serra circular, $3,71 \%$ do limite máximo.

Alves et al. (2002), analisando o ambiente de trabalho em um viveiro de propagação vegetal,

Tabela 1. Análise dos ruídos ( $\mathrm{dB}$ ) dos equipamentos analisados.

Table 1. Analysis of the noises $(\mathrm{dB})$ of the equipment examined.

\begin{tabular}{ccccc} 
Equipamentos & $\begin{array}{c}\text { Média } \\
\mathbf{d B}(\mathbf{A})\end{array}$ & $\begin{array}{c}\text { Desvio } \\
\text { padrão }\end{array}$ & $\begin{array}{c}\text { Número de } \\
\text { amostras }\end{array}$ & $\begin{array}{c}\mathbf{N}^{\circ} \text { mínimo de } \\
\text { amostras }\end{array}$ \\
\hline Respigadeira & 88,76 & 3,40 & 45 & 2,40 \\
\hline Serra circular & 88,16 & 9,03 & 45 & 17,14 \\
\hline Tupia & 84,24 & 3,26 & 45 & 2,46 \\
\hline
\end{tabular}


constatou que a intensidade do ruído variou de 73 a $90 \mathrm{~dB}$ durante a jornada de trabalho; ou seja, assim como no desdobro de madeira, a propagação florestal em tal viveiro atingiu valores acima da norma, exigindo o uso de protetores auriculares.

Segundo a NBR 5413 (Associação..., 1992), a operação em atividades de serraria encontrase na classe $B$, para a qual é necessário o nível de iluminância mínima variando entre 500 e 2000 lux. Essa amplitude deve-se às diferentes zonas de trabalho, como áreas internas com iluminação natural comprometida, setor de afiação e áreas de maior risco operacional.

A estrutura da serraria analisada (de concreto, antiga e mal planejada) impede que a iluminação natural adentre o ambiente de trabalho, fato que prejudica muito a iluminância média.

Pode-se verificar na Tabela 2 que o índice de iluminância média em todos os postos de trabalho não foi satisfatório, apresentando valores muito inferiores que 500 lux, estabelecidos pela NBR5413 (Associação..., 1992). O nível mais crítico foi observado na serra circular, representando esta apenas $6,9 \%$ do valor mínimo recomendado (500 lux).

Alves et al. (2002) também encontraram valores críticos de iluminação para determinados postos de trabalho, sendo na mesa de estaqueamento de macro encontrados os piores valores, variando de 100 a 300 lux, muito inferiores aos 500 lux solicitados pela NBR-5413 (Associação..., 1992).

Os valores obtidos pelas leituras do IBUTG para a análise de conforto térmico mostraram que, ao longo do tempo, a temperatura foi aumentando (Tabela 3), atingindo seu pico máximo na última medição, com $25,6^{\circ} \mathrm{C}$; a média das oito amostras foi de $24,57^{\circ} \mathrm{C}$.

De acordo com a NR 15 (Brasil, 1978), o trabalho em serraria é classificado como moderado, podendo o trabalhador operar em temperaturas de até $26,7^{\circ} \mathrm{C}$, sem que haja intervalos de descanso.

Clezar \& Nogueira (1999) ressaltam que a ventilação industrial visa garantir a pureza do ar, evitando problemas respiratórios, bem como problemas ambientais, visto o maior controle da poluição gerada. $\mathrm{O}$ uso de dispositivos de exaustão e circulação de ar na serraria, além de melhorar o
Tabela 2. Análise de iluminância média (lux) dos equipamentos utilizados.

Table 2. Analysis of average illuminance (lux) of the equipment used.

\begin{tabular}{|cc|}
\hline Equipamento & Média (lux) \\
\hline Tupia & 45,285 \\
\hline Bancada & 109,936 \\
\hline Serra circular & 34,886 \\
\hline Respigadeira & 36,878 \\
\hline
\end{tabular}

Tabela 3. Valores das medições do IBUTG, em ${ }^{\circ} \mathrm{C}$. Table 3. Measured values of the IBUTG, in ${ }^{\circ} \mathrm{C}$.

\begin{tabular}{|cc|}
\hline Horário das medições & IBUTG $\left({ }^{\circ} \mathbf{C}\right)$ \\
\hline $08: 30$ & 24,00 \\
\hline $08: 45$ & 23,80 \\
\hline $09: 00$ & 24,20 \\
\hline $09: 15$ & 24,40 \\
\hline $09: 30$ & 24,40 \\
\hline $09: 45$ & 25,00 \\
\hline $10: 00$ & 25,20 \\
\hline $10: 15$ & 25,60 \\
\hline Média & 24,57 \\
\hline
\end{tabular}

ambiente de trabalho, proporcionará melhor coleta dos resíduos gerados e maior ventilação do local de trabalho, contribuindo para reduzir os índices de temperatura e os riscos de acidentes.

Os resultados encontrados para o conforto térmico, embora tenham sido satisfatórios, podem não ser representativos, uma vez que a medição ocorreu em apenas um dia.

\section{CONCLUSÕES}

Os resultados das análises de ruído mostraram que o índice ao longo do dia é inaceitável e requer intervenções imediatas, como o uso de protetores auriculares por todos os funcionários, permitindo, assim, o trabalho contínuo durante o dia. Além disso, o uso de dispositivos de redução de ruídos nos motores e máquinas é necessário, e tornará o ambiente mais seguro e confortável.

Os valores médios encontrados da luminosidade foram inaceitáveis em todos os postos de trabalho. É necessária a instalação de lâmpadas de iluminação geral e lâmpadas de iluminação localizada mais potentes. Além disso, o uso de iluminação natural 
pode ser feito pela substituição de algumas telhas comuns por telhas de vidro ou fibra.

Embora o índice de conforto térmico tenha apresentado valores satisfatórios, cabe ressaltar que a adoção de sistemas de ventilação e exaustão proporcionará melhora em tal indicador, gerando um melhor ambiente de trabalho.

\section{AGRADECIMENTOS}

Ao proprietário da serraria estudada, pela disposição, pelos conselhos e pela ajuda na realização das amostragens.

\section{STATUS DA SUBMISSÃO}

Recebido: 20/12/2010

Aceito: 15/09/2011

Resumo publicado online: 20/09/2011

Artigo completo publicado: 30/09/2011

\section{AUTOR(ES) PARA CORRESPONDÊNCIA}

\section{Lucas Recla Lombardi}

Programa de Pós-graduação em Ciência Florestal, Departamento de Engenharia Florestal, Universidade Federal de Viçosa - UFV Av. P.H. Rolfs, s/n, Centro, CEP 36570-000, Viçosa, MG, Brasil e-mail: lucas.lombardi@ufv.br

\section{REFERENNCIAS}

Alves JU, Minetti LJ, Souza AP, Silva KR, Gomes JM, Fiedler NC. Avaliação do ambiente de trabalho na propagação de Eucalyptus spp. Revista Brasileira de Engenharia Agrícola e Ambiental 2002; 6(3):481-486.

Associação Brasileira de Normas Técnicas - ABNT. NBR 5413: iluminância de interiores. Rio de Janeiro: ABNT; 1992. $13 \mathrm{p}$.

Clezar CA, Nogueira ACR. Ventilação Industrial. Florianópolis: Ed UFSC; 1999.

Couto HA. Temas de saúde ocupacional - coletânea dos cadernos da Ergo. Belo Horizonte: Editora Ergo; 1987. 250p.

Fiedler NC, Souza AP. Ergonomia e Segurança do Trabalho no Indústria Madeireira. Vitória: Aquarius; 2007.

Iida I. Ergonomia: projeto e produção. São Paulo: Edgard Blucher; 2005. 614p.

Brasil. Lei no 6514, de 22 de dezembro de 1978. Norma Regulamentadora (NR), aprovada pela portaria SSMT $\mathrm{n}^{\circ} 12$, de 6 de junho de 1983. Alterar as Normas Regulamentadoras NR 7, NR 8, NR 9, NR 10, NR 12, NR 13, NR 14, e o Anexo VIII da NR 15, aprovados pela Portaria $\mathrm{n}^{\circ} 3.214$, de 08 de junho de 1978 , que possam a vigorar com a redação dada por esta Portaria. Diário Oficial da República Federativa do Brasil, Brasília, DF, 14 jun. 1983. anexo № 8

Brasil. Lei no 6514, de 22 de dezembro de 1977. Norma Regulamentadora (NR), aprovada pela portaria $\mathrm{n}^{\circ}$ 3214, de 8 de junho de 1978. Aprova as Normas Regulamentadoras - NR - do Capítulo V, Título II, da Consolidação das Leis do Trabalho, relativas a Segurança e Medicina do Trabalho. Diário Oficial da República Federativa do Brasil, Brasília, DF, jun 1978. 